\title{
Effect of Chlorinated Ethylenes on the Expression of Rat CYP2C
}

\author{
Takayuki Nakahama,* Masaki Mizuno, Minori Sekiguchi, Hiroki Sakamaki, \\ and Yoshio Inouye
}

School of Pharmaceutical Sciences, Toho University, 2-2-1 Miyama, Funabashi, Chiba 274-8510, Japan

(Received June 27, 2002; Accepted September 11, 2002)

\begin{abstract}
Chlorinated ethylenes (CEs) are known to be metabolized by CYP2C as well as CYP2E1 and CYP2B. The effects of CEs on the expression of the rat $C Y P 2 C$ gene in the liver and lung were comparatively studied in terms of the enzyme activity, and protein and mRNA contents. Tetrachloroethylene (PCE), trichloroethylene (TCE), and 1,1dichloroethylene (1,1-DCE) were injected at $0.5 \mathrm{~g} / \mathrm{kg}$ i.p. into male 7-week-old Wistar rats individually or in combination with phenobarbital (PB). The expression of CYP2C mRNA showed organ-specific properties without being detectable in the lung under the assay conditions employed in the present study. Individual CEs had no effect on the enzymatic activity of CYP2C estimated by $2 \alpha$-hydroxylation of testosterone ( $2 \alpha$-TSH), whereas PB markedly enhanced the enzymatic activity in the liver but not the lung microsomes, although it was highly susceptible to the suppressive effect of 1,1-DCE. A down-regulation of pulmonary enzyme activity was observed with PCE by an unknown mechanism when the animals were treated simultaneously with PB. 1,1-DCE was found to inhibit the expression of hepatic mRNA irrespective of the coexistence of $\mathrm{PB}$, and the same was true for CYP2C protein in the same organ to a lesser extent. In an analogy to our previous findings with other xenobiotic-metabolizing CYP forms such as CYP2B1/2 and CYP2E1, a potent suppressive effect of 1,1-DCE was observed with the maximum around $18 \mathrm{hr}$ after the treatment on both constitutive and PB-induced expression of CYP2C.
\end{abstract}

Key words — tetrachloroethylene, trichloroethylene, 1,1-dichloroethylene, CYP2C, $2 \alpha$-hydroxylation of testosterone

\section{INTRODUCTION}

Cytochrome $\mathrm{P} 450$ (P450 or CYP) is a superfamily of heme-containing enzymes that play a crucial role in the metabolism of a wide variety of exogenous and endogenous substances such as drugs, chemicals, steroids, and retinoids. On the other hand, the expression of $C Y P$ genes is modulated by various endogenous conditions and factors (diseases, hormones, cytokines, etc.) and exogenous factors (diet, exposure to environmental pollutant, etc.). A potent suppressive effect on the expression of hepatic P450 was observed in diabetes, ${ }^{1)}$ stress, ${ }^{2)}$ and especially inflammation. ${ }^{3)}$ Carlson and Billings reported that the expression of CYP1A2, 2B1/2, 2C11, and $3 \mathrm{~A} 2$ was suppressed by the combined treatment with interleukin (IL)-1, tumor necrosis factor (TNF)$\alpha$ and interferon (IFN)- $\gamma$ in primary cultured rat hepatocytes. ${ }^{4)}$ Recently, we observed potent inhibitory

*To whom correspondence should be addressed: School of Pharmaceutical Sciences, Toho University, 2-2-1 Miyama, Funabashi, Chiba 274-8510, Japan. Tel. \& Fax: +81-47-4722548; E-mail: nakahama@phar.toho-u.ac.jp effects of 1,1-dichloroethylene (1,1-DCE) on the expression of constitutive and phenobarbital (PB)induced P450s with trough values of CYP mRNAs being observed $18 \mathrm{hr}$ after treatment in an animal experiment using Wistar rats, ${ }^{5)}$ in marked contrast to their inductive effects in primary cultured hepatocytes (Nakahama et al., unpublished). The inflammation caused by 1,1-DCE in the whole animal could be responsible for these observations. Furthermore, the interference with the signal transduction triggered by $\mathrm{PB}$ resulting in the enhanced transcription of CYP2B in rats treated with 1,1-DCE was in good agreement with the observation of Abdel-Razak et $a l{ }^{6}{ }^{6}$ that IL-1 $\beta$ suppressed PB-inducible expression of CYPs in cultured rat hepatocytes.

CYP2C11 is a male-specific, constitutive P450 expressed at the highest level in the rat liver. The expression of CYP2C11 is controlled by a pulsatile pattern of growth hormone $(\mathrm{GH})$ secretion in male rats. In the case of female rats, however, the expression of CYP2C11 is down-regulated but CYP2C12, a female-specific counterpart, is induced by continuous secretion of GH, of which the plasma concen- 
trations are always measurable in the circulation. ${ }^{7)}$ The down-regulation of CYP2C11 observed in diabetic rats is associated not only with insulin deficiency but also with a glucagon surplus responsible for an increase in the amount of second messenger cAMP, which in turn activates protein kinase A. ${ }^{8)}$ It was recently reported that a putative negative nuclear factor (NF)- $\kappa$ B-responsive element, $n \kappa B-R E 1$, spanning the transcriptional start site of CYP2C11 was responsible for the transcriptional down-regulation of the CYP2C11 gene by $\mathrm{NF}-\kappa \mathrm{B}$ activated by proinflammatory cytokine IL- $1 \beta{ }^{9)}$

We reported that $\mathrm{CYP} 1 \mathrm{~A}, 2 \mathrm{~B}$, and $2 \mathrm{E} 1$ were mainly responsible for the metabolic activation of tetrachloroethylene (PCE), trichloroethylene (TCE), and 1,1-DCE, respectively. ${ }^{10)}$ On the contrary, chlorinated ethylenes (CEs) have been studied extensively for their effects on the expression of CYP1A, $2 \mathrm{~B}$, and $2 \mathrm{E} 1$ in animal models..$^{5,11-12)}$ Although CYP2C is reportedly one of the major P450 forms by which CEs are metabolized, ${ }^{13)}$ the effects of CEs on the expression of CYP2C have not been studied extensively. Therefore the present study focuses on the in vivo effects of CEs including TCE and PCE, both under stringent legislative control as environmental pollutants, on the expression of CYP2C in rat liver and lung.

\section{MATERIALS AND METHODS}

Reagents — PCE and TCE were purchased from Wako Pure Chemical Industries (Osaka, Japan). 1,1DCE was a product of Aldrich Chemical Co. (U.S.A.). Goat anti-rat CYP2C11 sera and peroxidase-labeled anti-goat IgG sera were obtained from Daiichi Chemical Co. (Tokyo, Japan). First-Strand Beads, PCR Beads, and Hybond-N+ were products of Amersham Biosciences (U.K.). Glyceraldehyde 3 phosphate dehydrogenase $(\mathrm{G} 3 \mathrm{PDH})$ primers and a G3PDH cDNA control probe were purchased from Clontech Laboratories (U.S.A.). BcaBEST (Takara, Japan) and $\left[\alpha{ }^{-}{ }^{32} \mathrm{P}\right]$ deoxycytidine $5^{\prime}$-triphosphate $([\alpha-$ $\left.{ }^{32} \mathrm{P}\right] \mathrm{dCTP}$ ) were used for labeling of cDNA probes. Animals and Treatment — Seven-week-old male Wistar rats (Clea, Japan) were divided into 8 groups, each consisting of 4-5 animals: PCE-treated, TCEtreated, and 1,1-DCE-treated groups; groups treated with a combination of individual $\mathrm{CEs}$ and $\mathrm{PB}$; vehicle-treated (control) group; and PB-treated (PB control) group. The rats were injected with the individual CEs (0.5 g/kg body weight i.p.) alone or si- multaneously with corn oil or PB $(80 \mathrm{mg} / \mathrm{kg}$ body weight). The livers and lungs were removed from the animals at the indicated times after treatment.

Microsomal Preparation — The microsomal preparations were carried out as described previously. ${ }^{14)}$ Briefly, the homogenates of the livers and lungs were centrifuged at $900 \mathrm{~g}$ for $5 \mathrm{~min}$ and then at $9000 \mathrm{~g}$ for $15 \mathrm{~min}$ at $4^{\circ} \mathrm{C}$. The microsomes were obtained from the $9000 \mathrm{~g}$ supernatants by centrifugation at $105000 \mathrm{~g}$ for $60 \mathrm{~min}$ at $4^{\circ} \mathrm{C}$. The microsomal protein content was determined using Lowry's method. ${ }^{15)}$

\section{Activity of Hydroxylation of Testosterone -} The enzymatic activity of CYP2C was determined by the $2 \alpha$-hydroxylation of testosterone ( $2 \alpha$-TSH). A mixture of the microsomes (0.5-2.0 mg protein), $50 \mathrm{mM}$ potassium phosphate ( $\mathrm{pH} 7.4), 1 \mathrm{mM}$ EDTA, $0.3 \mathrm{mM}$ testosterone, and a NADPH-generating system consisting of $0.8 \mathrm{mM}$ NADP, $8.0 \mathrm{mM}$ glucose 6-phosphate, 1 unit of glucose 6-phosphate dehydrogenase, and $6.0 \mathrm{mM}$ magnesium chloride in a final volume of $1.0 \mathrm{ml}$ was incubated for $10 \mathrm{~min}$ at $37^{\circ} \mathrm{C}$. After the addition of cortisol acetate as an internal standard, the reaction mixture was extracted with dichloromethane and the solvent was removed under a $\mathrm{N}_{2}$ stream. The metabolites of testosterone were analyzed as follows ${ }^{16)}$ : HPLC (Waters Co., Waters $600 \mathrm{E}$ ) equipped with octadecylsilane (ODS) column (Waters Symmetry $\mathrm{C}_{18}, 4.6 \times 100 \mathrm{~mm}$ ) was developed with a linear gradient of $40-45 \%$ aqueous acetonitrile for $12 \mathrm{~min}$ at a flow rate of $1.0 \mathrm{ml} / \mathrm{min}$. The eluates were monitored at $240 \mathrm{~nm}$.

Western Immunoblotting —_ An immunoblot analysis of microsomes was performed for the determination of CYP apoproteins. Sodium dodecyl sulfate-polyacrymide gel electrophoresis (SDSPAGE) was carried out with $10 \%$ acrylamide, according to the method of Laemmli. ${ }^{17)}$ The CYP apoproteins were electrophoretically transferred to a nitrocellulose sheet using a blotting apparatus (Transblot-SD, BioRad, U.S.A.). The sheet was treated with goat anti-rat CYP2C11 sera (cross reacting with CYP2C13, 2C6) and peroxidase-labeled anti-goat IgG sera. Chemiluminescence was recorded using the Western blotting detection reagent ECL Plus. The protein band-images were read using a Storm TM830 (Amersham Biosciences) and analyzed with Image Quant software.

Preparation of Probes — The amplified products obtained from the CYP2C11 mRNAs by reverse transcription-polymerase chain reaction (RT-PCR) (248 bp) were cloned into a pBluescript II 

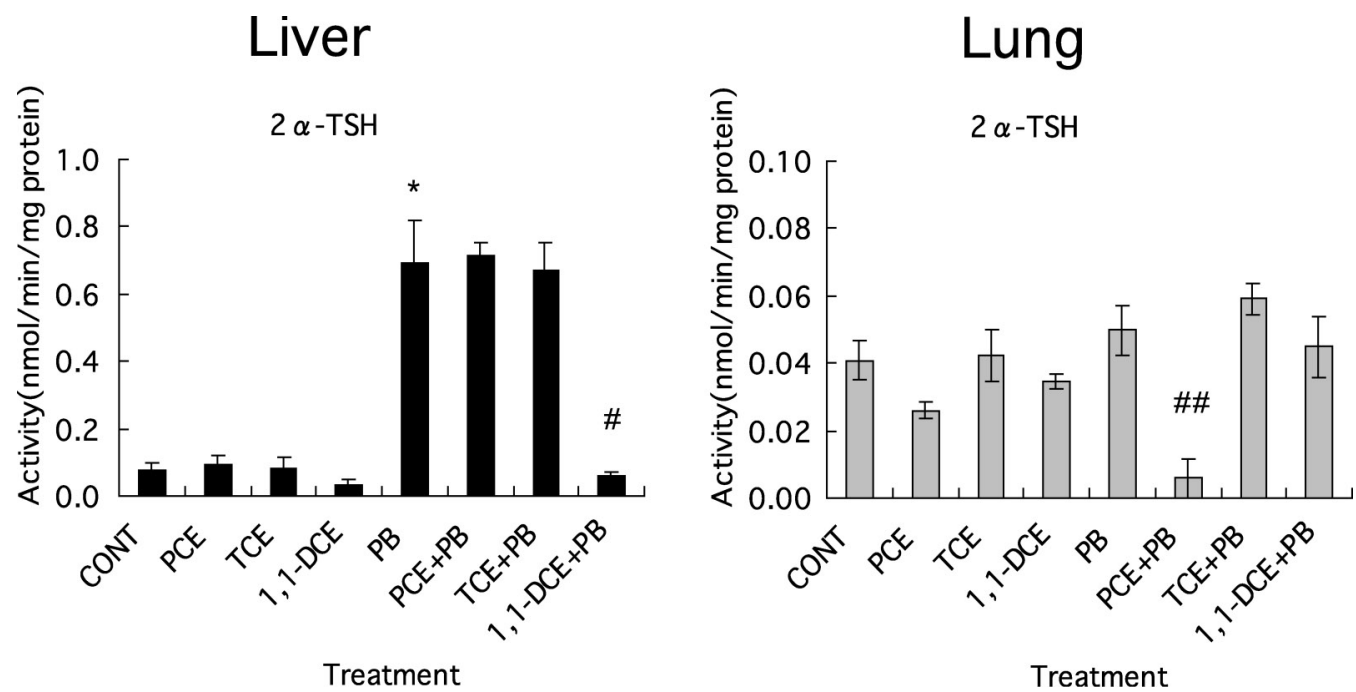

Fig. 1. $2 \alpha$-TSH Activity in Microsomes from the Livers and Lungs of Rats Treated with CEs and/or PB

The microsomal preparations from the livers and lungs of rats i.p. inoculated with PCE, TCE, 1,1-DCE (0.5 g/kg i.p.) and $/ \mathrm{or} \mathrm{PB}(80 \mathrm{mg} / \mathrm{kg}$ i.p.) were analyzed for their $2 \alpha$-TSH activities. The data are shown as the mean \pm S.E. for 5 rats with significant differences for the effect of CEs at $p<0.05$ (\#) and $p<0.01$ (\#\#), and for the effect of PB at $p<0.05(*)$ compared with the corresponding control groups.

(Stratagene) within the SmaI recognition site. The primers used were as follows: sense $5^{\prime}$-CTGCTGCTGCTGAAACACGTG-3'; and antisense 5'-GGATGAGCGATACTATCAC- $3^{\prime}$ The plasmid DNA amplified in the XL1-Blue cells was digested with Pst I and BamH I to obtain the CYP cDNA fragments, which were labeled with $\left[\alpha-{ }^{32} \mathrm{P}\right] \mathrm{dCTP}$ using a BcaBEST labeling kit (Takara), as well as a human G3PDH cDNA control probe (Clontech).

Northern Blotting — Total RNA (30 $\mu \mathrm{g})$ was separated electrophoretically on the denatured $1.2 \%$ agarose $/ 2.2 \mathrm{M}$ formaldehyde gel and stained with ethidium bromide for the analysis of mRNA. The gel was equilibrated in $20 \times \operatorname{SSPE}(3 \mathrm{M} \mathrm{NaCl}$, $200 \mathrm{mM}$ sodium phosphate, 20 mM EDTA, pH 7.4), and the RNA was transferred on to Hybond-N+ using a capillary blotting unit (Scotlab, U.K.). The membrane was prehybridized for $3 \mathrm{hr}$ at $42^{\circ} \mathrm{C}$ and hybridized for $20 \mathrm{hr}$ with a ${ }^{32} \mathrm{P}$-labeled cDNA probe at $42^{\circ} \mathrm{C}$. The membrane was exposed to Imaging Plate and analyzed using the Storm TM830.

Statistics — Significance was determined using Student's $t$-test. The 0.05 level of probability was adopted as a criterion of significance.

\section{RESULTS}

\section{Effects of CEs on Testosterone $2 \alpha$-Hydroxylase Activity}

The rats were treated with individual CEs, either with or without $\mathrm{PB}$, while those in the control groups were given a corn oil vehicle or PB. Using microsomal fractions prepared from the lungs and livers of animals after $24 \mathrm{hr}$, the $2 \alpha$-TSH activity attributable to the function of CYP2C was measured (Fig. 1).

A decrease in the hepatic $2 \alpha$-TSH activity was observed in the 1,1-DCE-treated group. The eightfold induction in the hepatic $2 \alpha$-TSH activity observed when treated with $\mathrm{PB}$ over the vehicle control was nullified by the coadministration of 1,1-DCE (Fig. 1, left). No effect was observed on the pulmonary $2 \alpha$-TSH activity in any group except for the animals treated with a combination of PB and PCE (Fig. 1, right).

\section{Effects of CEs on the Expression of CYP2C Apoprotein}

The determination of CYP2C protein was carried out by Western immunoblotting, and the protein levels after $24 \mathrm{hr}$ of CE treatment are shown in Fig. 2. Although the effect of individual CEs as well as $\mathrm{PB}$ on the protein levels in the liver and lung was not significant, a moderate down-regulation of hepatic protein expression was observed in the group of rats treated with 1,1-DCE in combination with PB.

\section{Effects of CEs on the Expression of CYP2C mRNA}

A marked decrease in the hepatic CYP2C mRNA expression was observed $18 \mathrm{hr}$ after the administra- 
(A) ${ }^{\text {CYP2C- }}$

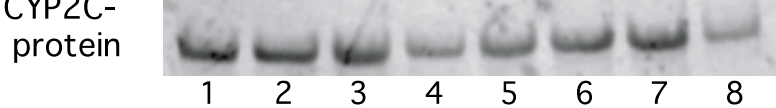

(B)

Liver

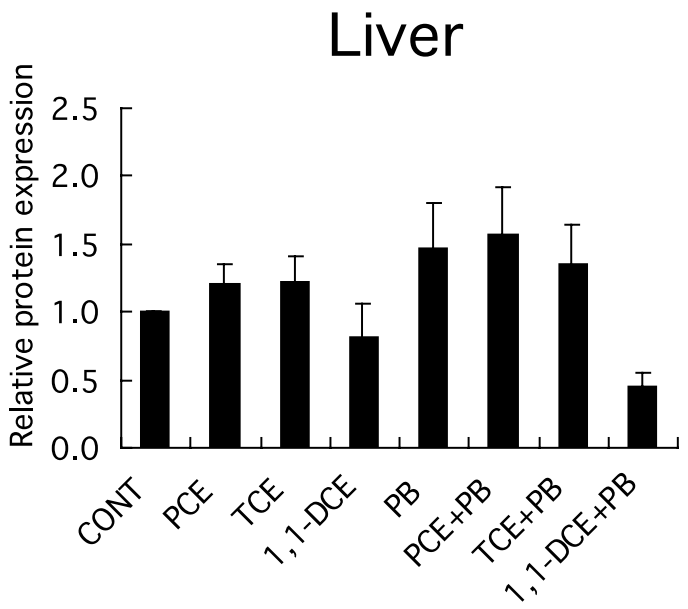

Treatment
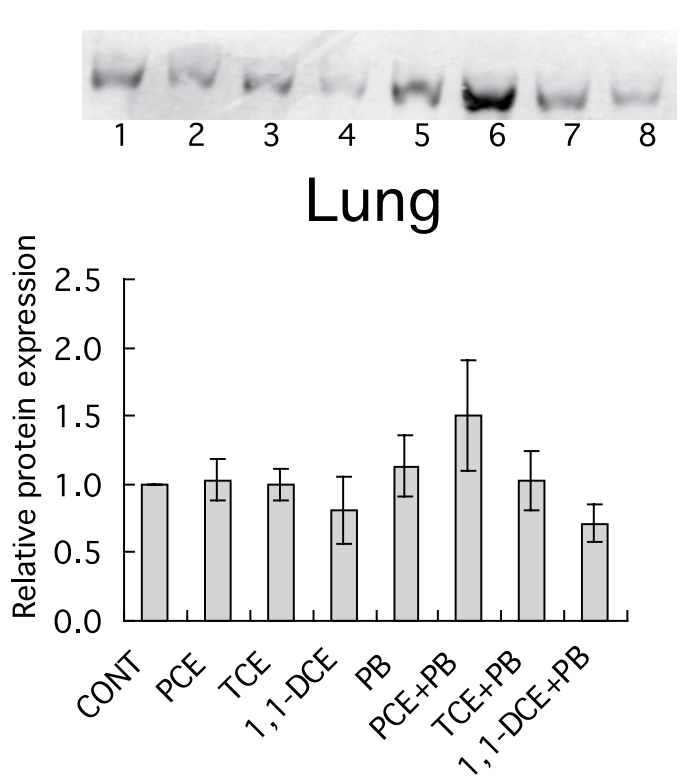

Treatment

Fig. 2. Expression of CYP2C Apoprotein in Microsomes from the Livers and Lungs of Rats Treated with CEs and/or PB

(A) Western immunoblots. CE monotreatment (left side): lane 1, control; lane 2, PCE; lane 3, TCE; lane 4, 1,1-DCE. Cotreatment with PB (right side): lane 5, PB; lane 6, PCE; lane 7, TCE; lane 8, 1,1-DCE. (B) Readings from Western blots. The data are shown as the mean \pm S.E. for 4 rats.

(A)

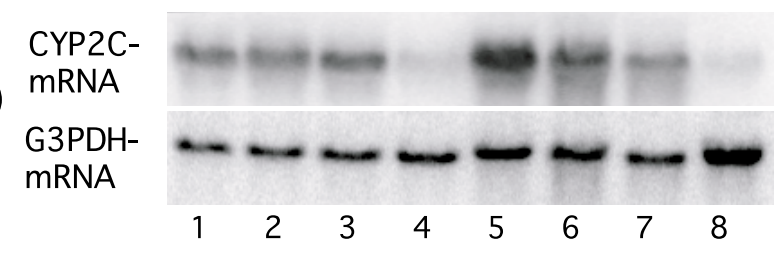

(B)

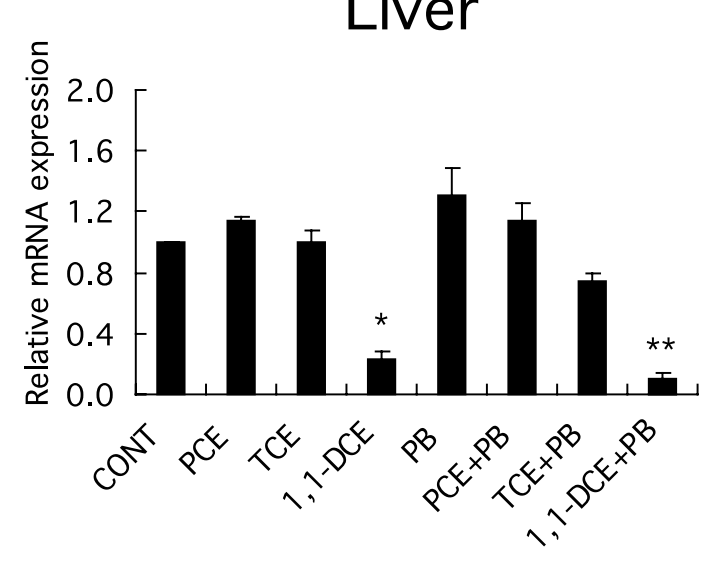

Treatment

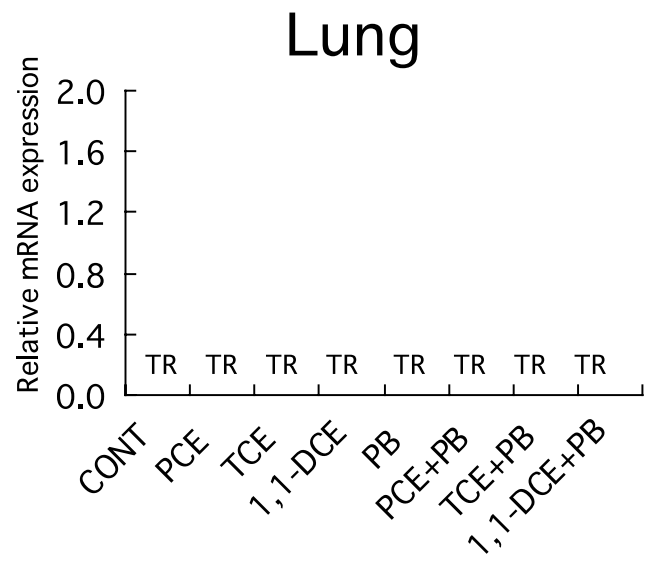

Treatment

Fig. 3. Expression of CYP2C mRNA in Microsomes from the Livers and Lungs of Rats Treated with CEs and/or PB

(A) Northern blots. Total RNA was isolated from the livers and lungs of rats inoculated with individual CEs $(0.5 \mathrm{~g} / \mathrm{kg}$ body weight i.p.) and/or PB $(80 \mathrm{mg} / \mathrm{kg}$ i.p.). The 30- $\mu \mathrm{g}$ portions were used for Northern blots. CE monotreatment (left side): lane 1, control; lane 2, PCE; lane 3, TCE; lane 4, 1,1DCE. Cotreatment with PB (right side): lane 5, PB; lane 6, PCE; lane 7, TCE; lane 8, 1,1-DCE. (B) Readings from Northern blots. The readings are the ratios of the band intensities of CYP2C mRNA and G3PDH mRNA normalized by those of the vehicle-treated rats, representing the mean \pm S.E. for 4 animals with significant differences compared to the vehicle- or PB-treated control group at $p<0.05(*)$ or $p<0.01(* *)$. TR: trace.

tion of 1,1-DCE irrespective of the coadministration of $\mathrm{PB}$, whereas no effect was observed in the animals treated with PCE and TCE individually and a lower rate of suppression was noted with a combination of TCE and PB. Slight expression of pulmonary CYP2C mRNA was observed. However, it was 
A

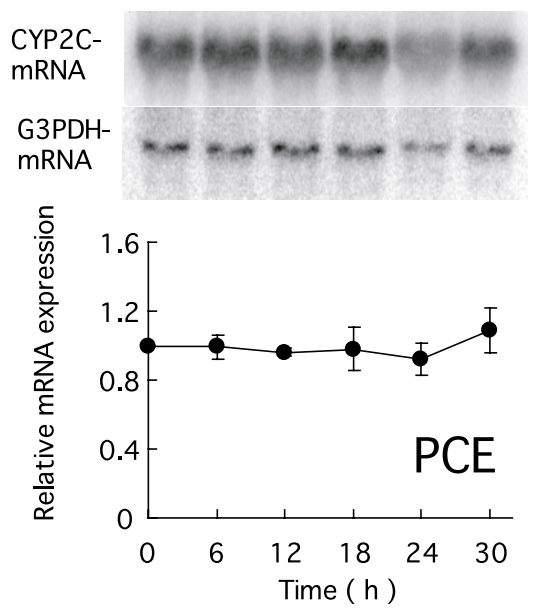

B

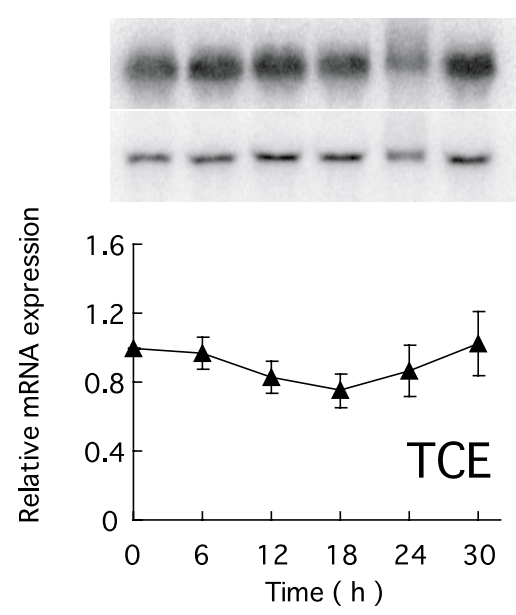

C
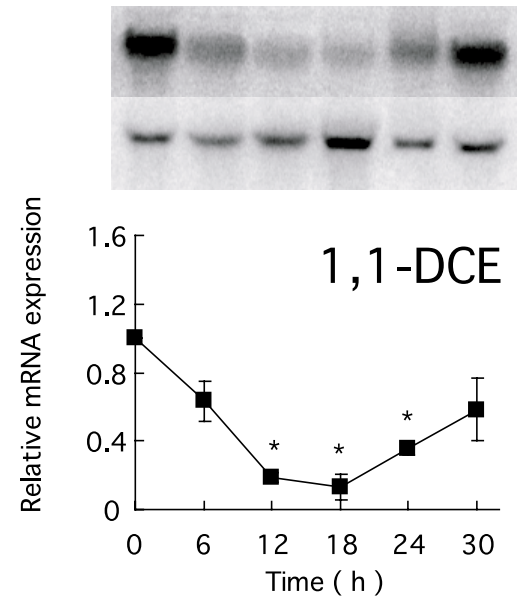

Fig. 4. Time-Dependent Expression of CYP2C mRNA in Livers of CE-treated Rats

The experimental procedures were the same as those shown in the legends to Fig. 3 except for the treatment periods. Panel A, PCE-treated rats; panel B, TCE-treated rats; panel C, 1,1-DCE-treated rats. *Significantly different from the 0 -hr control $(p<0.05)$.

too low to measure in any cases under the assay conditions employed (Fig. 3).

\section{Time-dependent Effects of CEs on the Expression of Hepatic CYP2C mRNA}

The effects of CEs on the expression of hepatic CYP2C mRNA were then monitored intermittently every $6 \mathrm{hr}$ during $30 \mathrm{hr}$ of treatment. Suppression was observed in the group administered 1,1-DCE even at $6 \mathrm{hr}$ with the highest suppression of about $90 \%$ at $18 \mathrm{hr}$ (Fig. 4). A significant suppression of the mRNA level remained at $24 \mathrm{hr}$. However, neither TCE nor PCE affected the expression of mRNA during the entire period of observation.

\section{DISCUSSION}

In the present study, PCE, TCE, and 1,1-DCE were studied for their effects on the expression of CYP2C, among which CYP2C11 is a major malespecific xenobiotic-metabolizing $\mathrm{P} 450$ preferentially expressed in rat liver, in both the presence and absence of PB. The inhibitory effect of 1,1-DCE on the expression of P450s observed in the whole animal did not occur in primary hepatocyte culture (unpublished data). The markedly suppressed CYP2C expression caused by 1,1-DCE was attributable partly to the chemically unstable nature of 1,1-DCE, because the inhibition of the expression of hepatic $\mathrm{P} 450$ s was rarely observed with the chemically more stable compounds PCE and TCE. Instead, PCE caused a temporary increase in the expression of CYP2B mRNA within $6 \mathrm{hr}$ after treatment. ${ }^{5)}$ PCE and TCE were placed under stringent legislative regulation in Japan under the Basic Law for Environmental Pollution Control (November 1993) as representative environmental pollutants due to their lack of biodegradability, which is in good accordance with their metabolical stabilitiy.

As in the case of CYP2B, the potentiation of expression of CYP2C was observed with $\mathrm{PB}$, although limited to the enzyme activity level. However, the lack of effect on the expression of protein and mRNA was in marked contrast with the transcriptional activation of the $C Y P 2 B$ gene. The mechanism for the PB-dependent induction of $\mathrm{P} 450$ expression might be diversified. Although the expression of CYP2C mRNA in the lung is negligible in comparison with that in the liver, it is noteworthy that pulmonary $2 \alpha$-TSH activity was obviously suppressed by a combination of PCE and PB, both of which were inactive individually.

We previously reported that 1,1-DCE reversed PB-induced expression of hepatic CYP2B mRNA to the basal level by interfering with signaling steps. ${ }^{11)}$ In the present study, the PB- dependent potentiation of hepatic $2 \alpha$-TSH activity was confirmed to be completely reversed to the basal level when the rats were treated with 1,1-DCE, although the details of the mechanisms controlling these findings remain to be elucidated. 


\section{REFERENCES}

1) Schenkman, J. B. (1991) Induction of diabetes and evaluation of diabetic state on P450 expression. Methods Enzymol., 206, 325-331.

2) Merrill, A. H., Jr., Wang, E., LaRocque, R., Mullins, R. E., Morgan, E. T., Hargrove, J. L., Bonkovsky, H. L. and Popova, I. A. (1992) Difference in glycogen, lipid and enzymes in livers from rats flown on COSMOS 2044. J. Appl. Physiol., 73(Suppl 1), S142-S147.

3) Morgan, E. T. (1989) Suppression of constitutive cytochrome P-450 gene expression in livers of rats undergoing an acute phase response to endotoxin. Mol. Pharmacol., 36, 699-707.

4) Carlson, T. J. and Billings, R. E. (1996) Role of nitric oxide in the cytokine-mediated regulation of cytochrome P-450. Mol. Pharmacol., 49, 796-801.

5) Mizuno, M., Nakahama, T. and Inouye, Y. (2001) Comparative study on correlation between chemical structure and effect on expression of cytochrome P450 mRNAs in rat among chlorinated ethylenes, tetrachloroethylene, trichloroethylene, 1,1-dichloroethylene. J. Health Sci., 47, 373-377.

6) Abdel-Razak, Z., Corcos, L., Fautrel, A. and Guillouzo, A. (1995) Interleukin-1 beta antagonizes phenobarbital induction of several major cytochromes P450 in adult rat hepatocytes in primary culture. FEBS Lett., 366, 159-164.

7) Morgan, E. T., MacGeoch, C. and Gustafsson, J.-A. (1985) Hormonal and developmental regulation of expression of the hepatic microsomal steroid $16 \alpha$ hydroxylase cytochrome $\mathrm{P}-450$ apoprotein in the rat. J. Biol. Chem., 260, 11895-11898.

8) Sidhu, J. S. and Omiecinsky, C. J. (1995) cAMPassociated inhibition of phenobarbital inducible cytochrome $\mathrm{P} 450$ gene expression in primary rat hepatocyte culture. J. Biol. Chem., 270, 12762-12773.
9) Iber, H., Chen, Q., Cheng, P.-Y. and Morgan, E. T. (2000) Suppression of CYP2C11 gene transcription by interleukin- 1 mediated by NF- $\mathrm{kB}$ binding at the transcription start site. Arch. Biochem. Biophys., 377, 187-194.

10) Nakahama, T., Maruyama, I., Endo, M. and Inouye, Y. (2001) Specificity in the metabolic activation of chlorinated ethylenes by cytochromes $\mathrm{P} 450$ in primary rat hepatocytes. J. Health Sci., 47, 36-39.

11) Nakahama, T., Mizuno, M., Otsuka, Y. and Inouye, Y. (2001) Comparative study on the mode of action of chlorinated ethylenes on the expression of rat CYP forms. J. Health Sci., 47, 278-287.

12) Nakahama, T., Sarutani, S. and Inouye, Y. (2000) Effects of chlorinated ethylenes on expression of rat CYP Forms: Comparative study on correlation between biological activities and chemical structures. J. Health Sci., 46, 251-258.

13) Nakajima, T., Wang, R. S., Elovaara, E., Park, S. S., Gelboin, H. V. and Vainio, H. (1992) A comparative study on the contribution of cytochrome P450 isozymes to metabolism of benzene, toluene and trichloroethylene in rat liver. Biochem. Pharmacol., 43, 251-257.

14) Nakahama, T., Sarutani, S. and Inouye, Y. (1999) Comparative study on the effect of trichloroethylene on the expression of P450 isoforms in rat lung and liver. J. Health Sci., 45, 8-14.

15) Lowry, O. H., Rosebrough, N. J., Farr, A., L. and Randall, R. J. (1951) Protein measurement with the folin phenol reagent. J. Biol. Chem., 193, 265-275.

16) Yamazoe, Y., Shimada, M., Murayama, N. and Kato, R. (1987) Suppression of levels of phenobarbitalinducible rat liver cytochrome P-450 by pituitary hormone. J. Biol. Chem., 262, 7423-7428.

17) Laemmli, U. K. (1970) Cleavage of structural proteins during the assembly of the head of bacteriophage T4. Nature (London), 227, 680-685. 